\section{Authors}

\title{
Development of DNA methylation-based epigenetic age predictors in loblolly pine (Pinus taeda)
}

\section{Running Title: Epigenetic aging in P. taeda} Steven T. Gardner ${ }^{1 *}$, Emily M. Bertucci ${ }^{1,2}$, Randall Sutton ${ }^{3}$, Andy Horcher ${ }^{3}$, Doug Aubrey ${ }^{1,4}$, Benjamin B. Parrott ${ }^{1,2}$

\section{Affiliations}

${ }^{1}$ Savannah River Ecology Laboratory, University of Georgia, Aiken, SC, 29802, USA

${ }^{2}$ Odum School of Ecology, University of Georgia, Athens, GA, 30602, USA

${ }^{3}$ US Forest Service Savannah River, New Ellenton, SC 29809, USA

${ }^{4}$ Warnell School of Forestry, University of Georgia, Athens, GA 30602, USA

*corresponding author

\section{Contact Information}

Email: steven.gardner@uga.edu

Phone: (256) 499-6715

Mail: Savannah River Ecology Laboratory

Drawer E

Savannah River Site, Bldg. 737-A

Aiken, SC 29803

Keywords: Epigenetic clock, DNA methylation, chronological age, biological age, Pinus taeda

\section{Abstract:}

Biological aging is connected to life history variation across ecological scales, as well as informing a basic understanding of age-related declines to organismal function. Altered DNA methylation dynamics are a conserved aspect of biological aging and have recently been modeled to predict chronological age among vertebrate species. In addition to their utility in estimating individual age, differences between chronological and predicted ages arise due to acceleration or deceleration of epigenetic aging, and these discrepancies are linked to disease risk and multiple life history traits. Although evidence suggests that patterns of DNA methylation can describe 
aging in plants, predictions with epigenetic clocks have yet to be performed. Here, we resolve the DNA methylome across $\mathrm{CpG}, \mathrm{CHG}$, and $\mathrm{CHH}$-methylation contexts in the loblolly pine tree

(Pinus taeda) and construct epigenetic clocks capable of predicting ages in this species within $8 \%$

of its lifespan. Although patterns of $\mathrm{CHH}$ methylation showed little association with age, both

\section{Introduction}

Alterations to the epigenome are a conserved hallmark of biological aging, and recent

49 findings have demonstrated that age-associated DNA methylation patterns can be modeled to

50 generate epigenetic age predictors capable of estimating chronological and biological age with

51 unprecedented accuracy (Berdyshev, Korotaev, Boiarskikh, \& Vaniushin, 1967; Christensen et

52 al., 2009; Hannum et al., 2013; Richardson, 2003). In one of the first DNA methylation-based age

53 predictors or "epigenetic clocks" developed by Horvath (2013), the methylation status of 353

54 cytosines predicts human chronological age with an error of \pm 3.6 years. Epigenetic clocks have

55 subsequently been developed in a variety of other mammalian (Horvath, 2013; Weidner et al.,

56 2014), avian (Raddatz et al., 2021), and fish species (Anastasiadi \& Piferrer, 2020; Bertucci,

57 Mason, Rhodes, \& Parrott, 2021; Mayne et al., 2020), and are currently being applied to 
58 biomedical and conservation problems, as well to questions regarding their relationship to the underlying biology of aging and senescence (Bertucci \& Parrott, 2020; Kabacik, Horvath, Cohen, \& Raj, 2018). However, whereas the phenomenon of epigenetic aging appears to be a conserved aspect of biological aging in vertebrates, age-associated changes to DNA methylation and their ability to predict chronological age in plants is relatively unexplored (Parrott \& Bertucci, 2019). DNA methylation refers to the covalent addition of a methyl group to the 5' carbon of cytosine nucleotides (Jung \& Pfeifer, 2015; Ng \& Adrian, 1999; Suzuki \& Bird, 2008), and although the functional consequences of these modifications vary across genomic context and taxonomic groups, DNA methylation is broadly associated with repressed transcriptional activity of genes and transposable elements through direct silencing and promotion of repressive chromatin states (Ng \& Adrian, 1999; Zilberman, 2008). Similar to vertebrates, changes in DNA methylation levels in plants are observed with exposure to stress, age, and development genomes (which almost exclusively occurs in CpG dinucleotides) DNA methylation in plant genomes is frequently observed within $\mathrm{CpG}, \mathrm{CHG}$ and $\mathrm{CHH}$ contexts (where $\mathrm{H}=\mathrm{A}, \mathrm{T}$, or $\mathrm{C}$ ). might relate to age-associated DNA methylation patterning is not resolved. 
81 (Horvath \& Raj, 2018; Parrott \& Bertucci, 2019; Xiao, Wang, \& Kong, 2019). Accelerated

82 epigenetic aging is associated with age related losses in organismal function and in humans, and

83 predicts risk for age-associated disease and mortality (Levine et al., 2018; Perna et al., 2016;

84 Zheng et al., 2016). In addition, epigenetic-to-chronological age discordance mirrors variation in

85 life history traits (Anderson et al., 2021; Hamlat, Prather, Horvath, Belsky, \& Epel, 2021). For

86 example, birth weight, age and size at maturity, as well as the timing of reproductive senescence

87 are all correlated to epigenetic age in humans, demonstrating intriguing links between aging

88 processes and life history variation (Binder et al., 2018; Ryan et al., 2018; Simpkin et al., 2015).

89 However, the links between the rate of epigenetic aging and variation in organismal function and

90 life history traits (including those with potential commercial implications) are largely unexplored

91 in plants.

Loblolly pine is a large tree with a broad geographic range spanning from southern New

93 Jersey to eastern Texas, including parts of northern Florida (Baker \& Langdon, 1990) and is

94 capable of living for up to 275 years (Baker \& Langdon, 1990). The loblolly pine is often

95 commercially harvested for timber and is also used to diversify forest habitats, control erosion,

96 and improve water quality (Baker \& Langdon, 1990). Research and management practices aimed

97 at improving growth and yield from loblolly pine stands often manipulate resource availability

98 (Albaugh, Lee Allen, Dougherty, \& Johnsen, 2004; Coyle, Aubrey, \& Coleman, 2016; Fox, Lee

99 Allen, Albaugh, Rubilar, \& Carlson, 2007). However, the underlying biological mechanisms

100 promoting optimal growth rates across variable environmental conditions remain unclear

101 (Albaugh et al., 2004), and resolving age-associated methylation patterns in plants may aid in

102 developing strategies for increasing traits such as leaf area and growth efficiency, which are

103 linked to stand productivity (Dubrovina \& Kiselev, 2016; Fox et al., 2007; Medlyn, Barrett, 
Landsberg, Sands, \& Clement, 2003; Samuelson, Stokes, Cooksey, \& McLemore III, 2001).

Furthermore, a recent study examining DNA methylation in Populus trichocarpa reported correlations between epimutation and age (Shahryary et al., 2020; Yao, Schmitz, \& Johannes, 2021), raising the possibility that these patterns could be used to predict other physiological traits such as plant growth (Hu, Morota, Rosa, \& Gianola, 2015). their genomic distributions among differing methylation contexts. We then test differing modeling strategies to develop a novel epigenetic clock for $P$. taeda, which can be used to investigate the factors most important to growth, development, and tree aging. This study demonstrates the utility of epigenetic clocks in non-vertebrate models and indicates that ageassociated DNA methylation may be a universal aspect of organismal aging.

\section{Materials and Methods}

\section{Sample Collection}

118 Between December 31, 2019 and January 14, 2020, cambium samples from standard coring procedures were obtained from 24 P. taeda individuals ranging from 1 to 119 years of age. This

120 study was conducted at the United States Department of Energy's Savannah River Site (Aiken,

121 SC, USA), a National Environmental Research Park. The United States Department of

122 Agriculture (USDA) Forest Service manages the natural resources of the Savannah River Site

123 (Kilgo and Blake 2005). Using records from the Forest Service, we identified stands which were

124 planted between 1 and 55 years prior and sampled three trees from each stand $(1,10,19,28,37$,

125 46, and 55 years old). Three additional trees of advanced age (82, 97, and 119 years old) were 
126 identified using core samples as planting records for older stands were unavailable. Cambium

127 samples from adult trees (>1-year) were taken at breast height (1.37 meters) using a metal hole

128 punch. Saplings (1-year old) were sampled at the base of the primary stem with a metal blade. All

129 samples were immediately stored in RNAlater at $-20^{\circ} \mathrm{C}$ until DNA extraction. Diameter at breast

130 height was measured using a diameter tape and height was measured using a TruPulse 200x

131 Rangefinder (Laser Technology, Inc., Centennial, CO).

\section{DNA extraction}

DNA was extracted from cambium tissue using Qiagen's DNeasy Plant Pro Kit (catalog \#

136 Briefly, samples were cut into small pieces using a sterile blade and then homogenized using a

137 Mini-Beadbeater (BioSpec, Bartlesville, OK) for 4-8 min at 2000 oscillations/min. DNA was

138 eluted in $50 \mu 1$ of the supplied elution buffer, and the concentration and purity of DNA samples

139 were assessed using a Qubit fluorometer 2.0 (Invitrogen, Carlsbad, CA) and Nanodrop

140 spectrometer (Thermo-Scientific, Waltham, MA), respectively.

\section{Reduced Representation Bisulfite Sequencing Library Preparation}

145 occurance of $\mathrm{CHG}$ methylation in plant genomes, we adapted the protocol by digesting genomic

146 DNA with the BsaWI restriction enzyme (Catalog \#R0567S, New England BioLabs, Ipswich,

147 MA) instead of MspI, as BsaWI cuts the recognition site $\mathrm{W}^{\wedge} \mathrm{CCGGW}$. Digestion efficiency of 
148 BsaWI in our samples was confirmed by visualizing digested genomic DNA from test samples

149 using standard gel electrophoresis. For library preparations, 200 ng of genomic DNA from each

150 sample was digested with 5 units/ng of BsaWI for $12 \mathrm{hr}$ at $60^{\circ} \mathrm{C}$, after which samples underwent

151 a 20 min heat inactivation of the restriction enzyme at $80^{\circ} \mathrm{C}$. To obtain sufficient library

152 concentrations, two RRBS libraries were prepared for each sample. In the second library

153 preparation, the protocol was further altered to add additional extension time in the final

154 amplification $\left(72^{\circ} \mathrm{C}\right.$ for 1 min during cycling and 10 min during final extension.) Libraries were

155 eluted in $22 \mu \mathrm{l}$ of the supplied elution buffer and stored at $-80^{\circ} \mathrm{C}$ until sequencing. Other than

156 these alterations, the manufacturer's protocol was followed exactly.

RRBS Sequencing, Quality Control, and Alignment

RRBS libraries were assessed for concentration and fragment size distribution on a

160 Fragment Analyzer (Advanced Analytical Technologies, Inc., Ames, IA) at the Georgia

161 Genomics and Bioinformatics Core at the University of Georgia. Libraries were then pooled and

162 sequenced single-end for 100 cycles on the Illumina NextSeq 2000 with $20 \%$ PhiX control added.

163 Two library preparations for each sample were sequenced across five high-output flow cells and

164 approximately 400 million reads from each flow cell were generated. The quality of the resulting

165 reads was assessed using FastQC (v0.11.5) (Andrews, 2017). Reads were trimmed using

166 TrimGalore! (v 0.4.5) to remove adapter sequences and low-quality reads (Phred score <25),

167 using the -rrbs option for RRBS data. Trimmed reads were concatenated into a single file and

168 aligned to a bisulfite converted index of the loblolly genome (Ptaeda2.0) using Bismark (v0.20.0)

169 (Krueger \& Andrews, 2011) allowing for one mismatch (option n -1). The subsequent alignments

170 were sorted and indexed using SAMtools (v 0.1.19) (Li et al., 2009). 
171

172

173

174

175

176

177

178

179

180

181

182

\section{File processing}

The resulting Bam files were analyzed using the methylKit package (Akalin et al., 2012) in $\mathrm{R}$ (version 4.0.5) (2021). An average of 18,177,435 (+/- 1,342,074) reads comprised each Bam file, and cytosines from each individual were divided into $\mathrm{CpG}, \mathrm{CHG}$, or $\mathrm{CHH}$ contexts using the read.context parameter in the processBismarkAln function of methylKit. To broadly assess ageassociated DNA-methylation, while also developing an epigenetic clock, we filtered our data using two approaches. In the first approach, we filtered out cytosines covered by $<5 \mathrm{x}$ reads and not represented in $<80 \%$ of samples. To ensure comparability across $\mathrm{CpG}, \mathrm{CHG}$, and $\mathrm{CHH}$ contexts, cytosines on opposite strands were not merged (destrand = FALSE). This data set is considered our "exploratory" data set, in which general age-associated patterns could be resolved. In the second approach, we increased coverage requirements $(\geq 10 x)$ to yield a dataset that could be used to construct epigenetic age predictors.

\section{Exploratory data set}

The resulting exploratory data set was analyzed using the files generated for $\mathrm{CpG}, \mathrm{CHG}$, and $\mathrm{CHH}$ cytosine-methylation contexts. We filtered out cytosines displaying zero or near-zero variance in methylation status across samples using the nearZeroVar function from the Classification And Regression Training (caret) package (Kuhn, 2015) in R. Following filtering of invariant cytosines, we performed Spearman correlations between the methylation status of each cytosine and chronological age using the corr.test function from the psych package (Revelle, 2019) in R. Given the exploratory nature of the downstream analyses, we considered cytosines with an absolute correlation coefficient greater than $0.5(|\mathrm{R}|>0.5)$ as being "age-associated", and 
192 those with p-values less than $0.05(P<0.05)$ following an FDR correction for multiple

193 comparisons as "significantly correlated" with age.

194 To assess genomic characteristics of age-associated and significantly correlated CpG,

$195 \mathrm{CHG}$, and $\mathrm{CHH}$ cytosines, we classified the genomic locations of all covered cytosines according

196 to genomic context within the P. taeda genome using the GenomicRanges package (Lawrence et

197 al., 2013). We first used CpG plot (Madeira et al., 2019) to identify CpG islands (CGIs;

198 parameters: widow $=100$, min len $=200$, minoe $=0.6$, minpc $=50$ ). We then used CGI

199 coordinates to generate coordinates for shore regions ( $\pm 2000 \mathrm{bp}$ from CGIs), and shelf regions $( \pm$

200 2000-4000 bp from CGIs) using Bedtools and Samtools (H. Li et al., 2009; Quinlan \& Hall,

201 2010). All remaining sites not falling in island, shore, or shelf regions were characterized as open

202 sea regions. Enrichment above background within each methylation context was performed with

203 binomial tests using all cytosines following invariant filtering within each context $(21,566$,

204 25,501, and 33,151 CpG, CHG, and CHH cytosines, respectively) as the background levels. To

205 identify genes in close proximity to cytosines according to age-associated methylation patterns,

206 we performed BLAST searches on 400 bp regions (200bp upstream and 200 bp downstream)

207 centered around each of the 35 cytosines from $\mathrm{CpG}$ and $\mathrm{CHG}$ contexts with the greatest

208 correlations with age.

Clock data set

Our exploratory analyses indicated that the methylation status of $\mathrm{CHH}$ cytosines was not

211 associated with age; thus, we only generated epigenetic clocks using CpG and CHG cytosines.

212 We first removed any invariant sites using the nearZero Var function from the caret package

213 (Kuhn, 2015) and performed imputation on missing data using a K-nearest neighbor (KNN) 
214 approach in the impute package (Hastie et al. 2021) in $\mathrm{R}$. We set $\mathrm{k}=2$ as each age group among

215 our samples was only represented by a maximum of three samples. We then split our data into a

216 training data set $(\mathrm{n}=19$; distributed among ages $1,10,19,28,37,46,55$, and 97 years old), and a

217 test data set $(\mathrm{n}=5$; ages: $1,28,55,82$, and 119 years old). Individuals comprising the test set

218 were selected by dividing the age range ( $1-119$ years) into 5 , then choosing 5 individuals with

219 ages separated by approximately 24 years.

220

221

222

223

224

225

226

227

228

229

230

231

232

233

234

235

\section{Elastic net clocks}

We trained elastic net models for $\mathrm{CpG}$ and $\mathrm{CHG}$ methylated cytosines using the glmnet package (Friedman, Hastie, \& Tibshirani, 2010) in R. We used an elastic net penalized regression model (alpha $=0.5$, family $=$ gaussian) to select CpG- and CHG-methylated cytosines and assign penalties to individual model coefficients using the subset of CpG-loci and CHG-loci. We used a leave-one-out cross validation approach $($ nfold $=19)$ to select the optimal lambda value (value resulting in minimum mean error) for the training set model ( $\mathrm{n}=19$ samples). We then used our training set model to predict ages of the individuals in our test set $(n=5)$. Following the generation of our elastic net epigenetic clock, we performed BLAST searches of $400 \mathrm{bp}$ regions centered around each clock cytosine and used GenomicRanges to determine the genomic contexts for these sites (genes and $\mathrm{CpG}$ islands, shores, shelves, or open seas).

\section{Pearson clocks}

To construct linear models capable of predicting age, we identified the top 5 and 10 cytosines with the greatest Pearson correlation with age $(|R|>0.5)$ from our training set using the corr.test function (using FDR correction, alpha = 0.05) from the psych package. We generated our linear models using the $\mathrm{lm}$ function in $\mathrm{R}$, and then used them to predict the ages of the 
236 individuals in our test data set. Following the generation of our linear model epigenetic clocks,

237 we performed BLAST searches of $400 \mathrm{bp}$ regions centered around clock cytosines and used

238 GenomicRanges to determine genomic context (genes and $\mathrm{CpG}$ islands, shores, shelves, or open

239 seas).

To compare performance of our elastic net and Pearson clocks, we used multiple regression to compare the mean absolute errors (MAE) generated when using each clock to

242 predict ages of trees from our test set. We used clock type as a factor and chronological age as a

243 covariate and corrected resulting $P$ values using Bonferroni correction for multiple comparisons.

244 Additionally, overfit of each clock to our training set was evaluated by comparing the MAE for

245 training and test sets from each clock using t-tests.

\section{Results}

Among the CpGs analyzed, 533 (2.47\%) displayed age-associated methylation, with 207

249 CpGs having positive correlations ( $\max \mathrm{R}=0.84$ ) and 326 having negative correlations ( $\min \mathrm{R}=$

1 positive) showed significant correlations with age. When examining locations of our age-

252 associated cytosines with respect to genomic contexts, CpG-methylated cytosines were enriched

253 in island $(P=4.85 \mathrm{e}-10)$ and shore regions $(P=0.038)$, while being depleted in shelf $(P=9 \mathrm{e}-04)$

254 and open-sea regions $(P=2.20 \mathrm{e}-06)$ (Figure 2$)$. Among the age-associated CpG-methylated sites

255 found in islands, many became hypomethylated with age (Table 1). Whereas this pattern was also

256 observed for CpGs in shore and open-seas, CpGs in shelf regions were more evenly split between

257 hypo- and hypermethylation with increasing age. Malate dehydrogenase (mdh), as well as $18 \mathrm{~S}$ 
258

259

and $26 \mathrm{~S}$ ribosomal genes of related pine species, were among the genes that a few of our methylated CpG-containing 400bp regions mapped to (Supplemental Table 1).

For CHG methylation, 869 cytosines $(3.41 \%)$ were age associated, with 350 displaying positive correlations ( $\max \mathrm{R}=0.87$ ) and 519 negatively correlated with age ( $\min \mathrm{R}=-0.89$;

Figure 1). Following FDR corrections, 70 of these 869 age-associated sites (60 hypomethylated and 10 hypermethylated) showed significant $(P<0.05)$ correlations with age. Compared to background levels, age-associated CHG cytosines were enriched in island regions $(P=3.62 \mathrm{e}-05)$ and were depleted in shores $(P=1.3 \mathrm{e}-03)$ (Figure 2$)$. The majority of CHG-methylated cytosines were hypomethylated with age, regardless of genomic context (Table 1). One of the top $35 \mathrm{CHG}$ age-associated cytosine sites mapped to an apparent homolog of mdh and became hypermethylated with age.

Within CHH-methylation contexts, $308(0.093 \%)$ cytosines were found to be ageassociated, with 187 displaying a positive correlation with age ( $\max R=76)$ and 121 negatively correlated to age (min $\mathrm{R}=-0.71$; Figure 1 ). However, following FDR corrections, no cytosines were significantly $(P<0.05)$ correlated with aging, and compared to background levels, there were no differences in the distributions of age-associated $\mathrm{CHH}$-methylated cytosines based on genomic context $(P>0.05)$. CHH-methylated cytosines found in island regions showed a trend of being mostly hypermethylated $(67 \%)$ with age (Table 1$)$, while $\mathrm{CHHs}$ found in shore regions were mostly hypomethylated (59\%) with age. Shelf-region CHHs were more evenly split between hypo and hypermethylation with age ( $48 \%$ vs $52 \%$ ), while most of the open-sea region CHH cytosines showed hypermethylation with age (63\%) (Figure 2).

\section{Construction of epigenetic clocks capable of predicting age}


Individual age predictors were initially constructed using elastic net regularized regression approaches using either $\mathrm{CpG}$ methylation, $\mathrm{CHG}$ methylation, or a combination of $\mathrm{CpG}$ and CHG methylation. All three elastic net clocks predicted ages of trees from our training set

283 within 0.62 years, and predicted ages were highly correlated with chronological ages for these

284 trees $\left(\mathrm{R}^{2}=0.99\right)$ (Table 2). However, the ability of these models to predict chronological ages of

285 trees in the test set were slightly lower and $\mathrm{R}^{2}$ values ranged from 0.79 to 0.90 , with the $\mathrm{CHG}$

286 model outperforming the $\mathrm{CpG}$ model, and the $\mathrm{CpG}$ and $\mathrm{CHG}$ combined model (Table 3)

287 performing the best.

In addition to our elastic net models, we manually constructed epigenetic clocks for each

methylation context $(\mathrm{CpG}, \mathrm{CHG}$, and $\mathrm{CpG}+\mathrm{CHG})$ using cytosines with the greatest Pearson

were predicted within 3.91 years and were highly correlated to chronological age $\left(\mathrm{R}^{2}=0.89\right.$ to performed better on the training set $\left(\mathrm{R}^{2}=0.94\right.$ to 0.98$)$; however, performance suffered on the

298 test set, $\mathrm{R}^{2}$ values ranging from 0.03 when using only $\mathrm{CpG}$-methylated cytosines to 0.87 when 299 using both CpG and CHG-methylated cytosines. 
total lifespan for $P$. taeda). Although MAE for our test set did not differ based on clock type $(P>$

0.05), MAE of predicted ages increased by $0.43( \pm 0.06)$ years with each chronological year

increase in age for trees in our test set $\left(t_{35}=7.04, P=1.02 \mathrm{e}-06\right)$ (Figures 3 and 4$)$. To assess the

potential overfit of our models, we compared the MAE of the training sets to those of test sets.

None of our models were overfit to our training set $(P>0.05)$ (Tables 2 and 4$)$.

We next used BLAST to assess if clock cytosines were proximal to specific genes.

Among the loci that mapped to known genes were mdh, NADH dehydrogenase, and rRNA (18S

and 26S). These loci were found in both methylation contexts ( $\mathrm{CpG}$ and $\mathrm{CHG})$ among our clocks,

and were distributed among all genomic contexts (islands, shores, shelves, and open seas). Both

mdh and NADH dehydrogenase sites became hypermethylated with age, and and sites mapping

to rRNA became hypomethylated with age (similar to patterns we observed in our exploratory

data set). Within our combined $\mathrm{CpG}+\mathrm{CHG}$ elastic net clock 10 of 47 cytosines returned hits

314 based on homology to these genes (Table 5). Among the 4 cytosines that mapped to mdh, the 2

315 CpG loci were located next to each other on the same scaffold, and both were in shore regions.

316 The remaining $2 \mathrm{CHG}$ loci that mapped to mdh were in shore and open sea regions on different

317 scaffolds. Similar to mdh, the 2 cytosines that mapped to NADH dehydrogenase were also

318 located on different scaffolds, 1 being a $\mathrm{CpG}$ and located in an open sea region and the other a

319 CHG found in an open sea region. Cytosines in rRNA genes (18S and 26S) were CpG-

321 found in island, shore, and open sea regions on differing scaffolds of the P.taeda genome,

322 respectively. For annotations of cytosines from $\mathrm{CpG}$ and $\mathrm{CHG}$ clocks, see Supplemental Tables 


\section{Discussion}

We demonstrate the first use of methylation patterns to generate epigenetic clocks for $P$.

taeda, which are capable of predicting chronological ages within $\sim 8 \%$ of the total lifespan (275

years) of this species. Although there were no differences in test set MAE among our clocks,

predicted ages from clocks combining methylation in both contexts showed the highest

correlations with age, indicating that methylation in both contexts is useful when predicting ages

for P. taeda and potentially other plant species. Although age-associated $\mathrm{CpG}$ and $\mathrm{CHG}$

methylation was distributed across genomic regions, we observed an enrichment of age-

associated $\mathrm{CpG}$ methylation within island and shore regions, and CHG methylation in island

regions. Within both methylation contexts, age-associated methylation mostly resulted in

hypomethylation, regardless of genomic (island, shore, shelf, or open sea) context. In regard to

potential functional implications, only $\mathrm{CpG}$-methylation has been previously associated with

gene expression in P. taeda (Takuno et al., 2016). As increased CpG methylation at promoter

sequences (commonly associated with $\mathrm{CpG}$ island regions) is associated with reduced expression

of downstream genes (Gehring \& Henikoff, 2007), hypomethylation at many island-region sites

may indicate that expression of specific genes increases with age in $P$. taeda. In contrast to CpG-

methylation, CHG-methylation is associated with gene splicing (Chaudhary, Jabre, \& Syed,

2021; Zhang, Lang, \& Zhu, 2018). Alterations in CHG-methylation status can affect the proper

splicing of genes (Chaudhary et al., 2021; Zhang et al., 2018) which can have deleterious

consequences (Ong-Abdullah et al., 2015). When comparing age-related changes in methylation

status among cytosines from both $\mathrm{CpG}$ and $\mathrm{CHG}$ contexts mapping to known genes in our

BLAST searches, gains and losses were consistent for sites mapping to similar genes for both

contexts. Thus, our findings taken together with current functional understanding indicates a 
347 possible link between epigenetic aging and increases in gene expression and splicing variation

348 with age. Compared to $\mathrm{CpG}$ and $\mathrm{CHG}$-methylation, $\mathrm{CHH}-$ methylation in plants has largely been

349 associated with transposable element silencing (Dubin et al., 2015), and rates of epimutations in

350 transposable element regions are generally low (van der Graaf et al., 2015). Thus, the stability of

$351 \mathrm{CHH}$ methylation through development could explain the poor associations between $\mathrm{CHH}$

352 methylation and aging observed in the current study.

Although the majority of cytosines in our analyses did not map to annotated genes, the

354 expression of critical genes involved in conserved molecular pathways that regulate life-history

355 traits has been observed to influence multiple physiological processes (Partridge \& Gems, 2002;

356 Perls et al., 2002; Flatt \& Partridge, 2018). Among the genes proximal to several of our age-

357 associated $\mathrm{CpG}$ and $\mathrm{CHG}-$ methylated sites in the exploratory and clock data sets were malate

358 dehydrogenase (mdh), NADH dehydrogenase, and 18S and 26S rRNA. The expression of mdh, a

359 multi-subunit metabolic enzyme in many organisms including plants (Longo \& Scandalios, 1969;

360 Yudina, 2012), has been linked to respiration and $\mathrm{CO}_{2}$ assimilation rates, and normal plant

361 growth and development (Tomaz et al., 2010). Expression has been shown to increase with age,

362 which is postulated to maintain aerobic metabolism (Sharma \& Patnaik, 1982). NADH

363 dehydrogenase, another important metabolic enzyme involved in the electron transport chain

364 (Weiss, Friedrich, Hofhaus, \& Preis, 1992), is also associated with plant growth and development

365 (Sweetman et al., 2019). Proper subunit splicing of this enzyme is essential for its function

366 (Bonen, 2008; Malek \& Knoop, 1998), with defective splicing leading to decreased activity of the

367 electron transport chain, slower growth, and delayed germination and phenotypic development

368 (Hsieh et al., 2015). Expression and activity of rRNA have been shown to increase with increased 
metabolic demands (Russell \& Zomerdijk, 2005), also affecting growth, cell adaptation, stress responses, and cell proliferation (Russell \& Zomerdijk, 2005). Increased methylation near rRNA

371 promoter regions greatly reduces expression (Ghoshal et al., 2004; Zatsepina et al., 1993);

372 therefore, the loss of methylation we observed for cytosines proximal to $18 \mathrm{~S}$ and $26 \mathrm{~S}$ rRNA

373 genes in island and shore regions coupled with the methylation gains we observed for CpG-

374 methylated cytosines near mdh and NADH dehydrogenase in shore and open sea regions may

375 indicate expression of these genes increases to match increasing metabolic demands as $P$. taeda

376 trees age. If so, an increased requirement for proper splicing of NADH and mdh would be needed

377 (Gendrel, Lippman, Yordan, Colot, \& Martienssen, 2002; Jeddeloh, Stokes, \& Richards, 1999),

378 which might explain the increased CHG-methylation near these genes with age; although these

379 predictions require further evaluation.

Beyond their ability to predict chronological age, the epigenetic clocks developed here are

likely to find utility in forest management applications and addressing questions surrounding the

basic biology of aging. The directionality and magnitude of epigenetic-to-chronological age

discordance in humans and other vertebrates correlates to variation in life history traits (Anderson

et al., 2020; Hamlat et al., 2021; Ryan, 2021). Variation in life history traits can have

consequences for stand productivity (Kellner \& Swihart, 2016; Schulze, 2003). If epigenetic-to-

chronological age discordance, especially in early life, is connected to variation in tree growth,

387 productivity, wood quality, and/or responses to disturbances, epigenetic clocks might inform

388 breeding programs and could be used in evaluating efficiencies of experimental manipulations to

389 increase early-life growth and subsequent wood yield from managed P. taeda stands (Baker \&

390 Langdon, 1990; Clason, 1989). Age-associated variation in DNA methylation patterns is also 
associated with species-specific lifespans in vertebrates (Mayne, Berry, Davies, Farley, \&

methylation patterns might be used to estimate lifespan and yield insights into the underlying genetic and epigenetic determinants across different plant species.

396 The $P$. taeda genome, like that of many tree species, is quite large (20 billion base pairs) (Neale more cost-efficient technical approaches (e.g. amplicon sequencing, bait capture techniques) are likely needed if measures of epigenetic age are to be scaled to stand and population applications (Meek \& Larson, 2019). Due to the age distributions of our sampled trees, age predictions for our

401 individuals older than 55 years of age were poor, which may have contributed to the greater MAE 402 from our clocks compared to those predicting ages for many vertebrate species (Bertucci et al., 403 2021; Bors et al., 2021; Lemaître et al., 2020; Meer, Podolskiy, Tyshkovskiy, \& Gladyshev, 404 2018; Stubbs et al., 2017). As we initially removed sites not present in at least $80 \%$ of our 405 individuals and many of our trees were within stand ages (Cunningham, n.d.; Li et al., 1999; Stiff $406 \&$ Stansfield, 2003), additional sampling of older trees could allow for retention of higher numbers of cytosine sites whose methylation status remains dynamic in later life, allowing for 408 more accurate age predictions of older trees in further clock studies. Despite these limitations, we 409 clearly demonstrate the relationship between DNA methylation and chronological age in a long410 lived tree species and indicate that alterations in DNA methylation may be a universal aspect of 411 aging across the tree of life.

\section{Acknowledgements}


413

414

415

416

417

418

We would like to thank Samantha Bock for her assistance with bioinformatic work, as well as the members of the Parrott lab at SREL for their feedback pertaining to the results of this study. This study was supported in part by the USDA Forest Service-Savannah River, under Interagency DEEM0003622 with the U.S. Department of Energy, the National Science Foundation (Award \#2026210, BBP), and the U.S. Department of Energy Office of Environmental Management under award number DE-EM0004391 to the University of Georgia Research Foundation.

\section{References}

Akalin, A., Kormaksson, M., Li, S., Garrett-Bakelman, F. E., Figueroa, M. E., Melnick, A., \& Mason, C. E. (2012). methylKit: A comprehensive R package for the analysis of genomewide DNA methylation profiles. Genome Biology, 13(10), R87. doi: 10.1186/gb-2012-13$10-\mathrm{r} 87$

Albaugh, T. J., Lee Allen, H., Dougherty, P. M., \& Johnsen, K. H. (2004). Long term growth responses of loblolly pine to optimal nutrient and water resource availability. Forest Ecology and Management, 192(1), 3-19. doi: 10.1016/j.foreco.2004.01.002

Anastasiadi, D., \& Piferrer, F. (2020). A clockwork fish: Age prediction using DNA methylationbased biomarkers in the European seabass. Molecular Ecology Resources, 20(2), 387397. doi: 10.1111/1755-0998.13111

Anderson, J. A., Johnston, R. A., Lea, A. J., Campos, F. A., Voyles, T. N., Akinyi, M. Y., ... Tung, J. (2020). The costs of competition: High social status males experience accelerated epigenetic aging in wild baboons (p. 2020.02.22.961052). doi: 10.1101/2020.02.22.961052

Anderson, J. A., Johnston, R. A., Lea, A. J., Campos, F. A., Voyles, T. N., Akinyi, M. Y., ... Tung, J. (2021). High social status males experience accelerated epigenetic aging in wild baboons. ELife, 10, e66128. doi: 10.7554/eLife.66128

Andrews, S. (2017). FastQC: a quality control tool for high throughput sequence data. 2010.

Ausin, I., Feng, S., Yu, C., Liu, W., Kuo, H. Y., Jacobsen, E. L., ... Wang, H. (2016). DNA methylome of the 20-gigabase Norway spruce genome. Proceedings of the National Academy of Sciences, 113(50), E8106-E8113. doi: 10.1073/pnas.1618019113

Baker, J. B., \& Langdon, O. G. (1990). Pinus taeda L. Loblolly pine. Silvics of North America, 1, 497-512.

Berdyshev, G. D., Korotaev, G. K., Boiarskikh, G. V., \& Vaniushin, B. F. (1967). Nucleotide composition of DNA and RNA from somatic tissues of humpback and its changes during spawning. Biokhimiia (Moscow, Russia), 32(5), 988-993.

Bertucci, E. M., Mason, M. W., Rhodes, O. E., \& Parrott, B. B. (2021). The aging DNA methylome reveals environment-by-aging interactions in a model teleost ( $\mathrm{p}$. 2021.03.01.433371). doi: 10.1101/2021.03.01.433371 
Bertucci, E. M., \& Parrott, B. B. (2020). Is CpG Density the Link between Epigenetic Aging and Lifespan? Trends in Genetics, 36(10), 725-727. doi: 10.1016/j.tig.2020.06.003

Binder, A. M., Corvalan, C., Mericq, V., Pereira, A., Santos, J. L., Horvath, S., .. Michels, K. B. (2018). Faster ticking rate of the epigenetic clock is associated with faster pubertal development in girls. Epigenetics, 13(1), 85-94. doi: 10.1080/15592294.2017.1414127

Bonen, L. (2008). Cis- and trans-splicing of group II introns in plant mitochondria. Mitochondrion, 8(1), 26-34. doi: 10.1016/j.mito.2007.09.005

Bors, E. K., Baker, C. S., Wade, P. R., O’Neill, K. B., Shelden, K. E. W., Thompson, M. J., ... Horvath, S. (2021). An epigenetic clock to estimate the age of living beluga whales. Evolutionary Applications, 14(5), 1263-1273. doi: https://doi.org/10.1111/eva.13195

Chaudhary, S., Jabre, I., \& Syed, N. H. (2021). Epigenetic differences in an identical genetic background modulate alternative splicing in A. thaliana. Genomics, 113(6), 3476-3486. doi: 10.1016/j.ygeno.2021.08.006

Christensen, B. C., Houseman, E. A., Marsit, C. J., Zheng, S., Wrensch, M. R., Wiemels, J. L., ... Kelsey, K. T. (2009). Aging and Environmental Exposures Alter Tissue-Specific DNA Methylation Dependent upon CpG Island Context. PLOS Genetics, 5(8), e1000602. doi: 10.1371/journal.pgen.1000602

Clason, T. R. (1989). Early Growth Enhancement Increases Loblolly Pine Rotation Yields. Southern Journal of Applied Forestry, 13(2), 94-99. doi: 10.1093/sjaf/13.2.94

Coyle, D. R., Aubrey, D. P., \& Coleman, M. D. (2016). Growth responses of narrow or broad site adapted tree species to a range of resource availability treatments after a full harvest rotation. Forest Ecology and Management, 362, 107-119. doi: 10.1016/j.foreco.2015.11.047

Cunningham, K. (n.d.). Managing Loblolly Pine Stands...from A to Z. 6.

Dubin, M. J., Zhang, P., Meng, D., Remigereau, M.-S., Osborne, E. J., Paolo Casale, F., ... Nordborg, M. (2015). DNA methylation in Arabidopsis has a genetic basis and shows evidence of local adaptation. ELife, 4, e05255. doi: 10.7554/eLife.05255

Dubrovina, A. S., \& Kiselev, K. V. (2016). Age-associated alterations in the somatic mutation and DNA methylation levels in plants. Plant Biology, 18(2), 185-196. doi: 10.1111/plb.12375

Flatt, T., \& Partridge, L. (2018). Horizons in the evolution of aging. BMC Biology, 16(1), 1-13.

Fox, T. R., Lee Allen, H., Albaugh, T. J., Rubilar, R., \& Carlson, C. A. (2007). Tree nutrition and forest fertilization of pine plantations in the southern United States. Southern Journal of Applied Forestry, 31(1), 5-11.

Friedman, J., Hastie, T., \& Tibshirani, R. (2010). Regularization Paths for Generalized Linear Models via Coordinate Descent. Journal of Statistical Software, 33(1), 1-22.

Gehring, M., \& Henikoff, S. (2007). DNA methylation dynamics in plant genomes. Biochimica et Biophysica Acta (BBA) - Gene Structure and Expression, 1769(5), 276-286. doi: 10.1016/j.bbaexp.2007.01.009

Gendrel, A.-V., Lippman, Z., Yordan, C., Colot, V., \& Martienssen, R. (2002). Dependence of Heterochromatic Histone H3 Methylation Patterns on the Arabidopsis Gene DDM1. Science (New York, N.Y.), 297, 1871-1873. doi: 10.1126/science.1074950

Ghoshal, K., Majumder, S., Datta, J., Motiwala, T., Bai, S., Sharma, S. M., ... Jacob, S. T. (2004). Role of Human Ribosomal RNA (rRNA) Promoter Methylation and of Methyl- 
CpG-binding Protein MBD2 in the Suppression of rRNA Gene Expression *. Journal of Biological Chemistry, 279(8), 6783-6793. doi: 10.1074/jbc.M309393200

Hamlat, E. J., Prather, A. A., Horvath, S., Belsky, J., \& Epel, E. S. (2021). Early life adversity, pubertal timing, and epigenetic age acceleration in adulthood. Developmental Psychobiology, 63(5), 890-902. doi: 10.1002/dev.22085

Hannum, G., Guinney, J., Zhao, L., Zhang, L., Hughes, G., Sadda, S., ... Zhang, K. (2013). Genome-wide Methylation Profiles Reveal Quantitative Views of Human Aging Rates. Molecular Cell, 49(2), 359-367. doi: 10.1016/j.molcel.2012.10.016

Hastie T., Tibshirani, R., Narasimhan, B., \& Chu, G. (2021). impute: impute: Imputation for microarray data. $\mathrm{R}$ package version 1.68.0.

Horvath, S. (2013). DNA methylation age of human tissues and cell types. Genome Biology, 14(10), 1-20.

Horvath, S., \& Raj, K. (2018). DNA methylation-based biomarkers and the epigenetic clock theory of ageing. Nature Reviews Genetics, 19(6), 371-384.

Hsieh, W.-Y., Liao, J.-C., Chang, C.-Y., Harrison, T., Boucher, C., \& Hsieh, M.-H. (2015). The SLOW GROWTH3 Pentatricopeptide Repeat Protein Is Required for the Splicing of Mitochondrial NADH Dehydrogenase Subunit7 Intron 2 in Arabidopsis. Plant Physiology, 168(2), 490-501. doi: 10.1104/pp.15.00354

Hu, Y., Morota, G., Rosa, G. J. M., \& Gianola, D. (2015). Prediction of Plant Height in Arabidopsis thaliana Using DNA Methylation Data. Genetics, 201(2), 779-793. doi: 10.1534/genetics.115.177204

Jeddeloh, J. A., Stokes, T. L., \& Richards, E. J. (1999). Maintenance of genomic methylation requires a SWI2/SNF2-like protein. Nature Genetics, 22(1), 94-97. doi: 10.1038/8803

Jiang, C., Mithani, A., Belfield, E. J., Mott, R., Hurst, L. D., \& Harberd, N. P. (2014). Environmentally responsive genome-wide accumulation of de novo Arabidopsis thaliana mutations and epimutations. Genome Research, 24(11), 1821-1829. doi: $10.1101 /$ gr. 177659.114

Jung, M., \& Pfeifer, G. P. (2015). Aging and DNA methylation. BMC Biology, 13(1), 7. doi: 10.1186/s12915-015-0118-4

Kabacik, S., Horvath, S., Cohen, H., \& Raj, K. (2018). Epigenetic ageing is distinct from senescence-mediated ageing and is not prevented by telomerase expression. Aging (Albany NY), 10(10), 2800-2815. doi: 10.18632/aging.101588

Kellner, K. F., \& Swihart, R. K. (2016). Timber harvest and drought interact to impact oak seedling growth and survival in the Central Hardwood Forest. Ecosphere, 7(10), e01473. doi: $10.1002 /$ ecs2.1473

Krueger, F., \& Andrews, S. R. (2011). Bismark: A flexible aligner and methylation caller for Bisulfite-Seq applications. Bioinformatics, 27(11), 1571-1572. doi: 10.1093/bioinformatics/btr167

Kuhn, M. (2015). Caret: Classification and regression training. Astrophysics Source Code Library, ascl-1505.

Law, J. A., \& Jacobsen, S. E. (2010). Establishing, maintaining and modifying DNA methylation patterns in plants and animals. Nature Reviews Genetics, 11(3), 204-220.

Lawrence, M., Huber, W., Pagès, H., Aboyoun, P., Carlson, M., Gentleman, R., .. Carey, V. J. (2013). Software for Computing and Annotating Genomic Ranges. PLOS Computational Biology, 9(8), e1003118. doi: 10.1371/journal.pcbi.1003118 
Lemaître, J.-F., Rey, B., Gaillard, J.-M., Régis, C., Gilot, E., Pellerin, M., ... Horvath, S. (2020). Epigenetic clock and DNA methylation studies of roe deer in the wild (p. 2020.09.21.306613). doi: 10.1101/2020.09.21.306613

Levine, M. E., Lu, A. T., Quach, A., Chen, B. H., Assimes, T. L., Bandinelli, S., ... Horvath, S. (2018). An epigenetic biomarker of aging for lifespan and healthspan. Aging (Albany NY), 10(4), 573-591. doi: 10.18632/aging.101414

Li, B., Mckeand, S., \& Weir, R. (1999). Tree improvement and sustainable forestry-Impact of two cycles of loblolly pine breeding in the USA. For. Genet., 6, 229-234.

Li, H., Handsaker, B., Wysoker, A., Fennell, T., Ruan, J., Homer, N., .. 1000 Genome Project Data Processing Subgroup. (2009). The Sequence Alignment/Map format and SAMtools. Bioinformatics, 25(16), 2078-2079. doi: 10.1093/bioinformatics/btp352

Longo, G. P., \& Scandalios, J. G. (1969). Nuclear gene control of mitochondrial malic dehydrogenase in maize. Proceedings of the National Academy of Sciences, 62(1), 104111.

Madeira, F., Park, Y. M., Lee, J., Buso, N., Gur, T., Madhusoodanan, N., ... Finn, R. D. (2019). The EMBL-EBI search and sequence analysis tools APIs in 2019. Nucleic Acids Research, 47(W1), W636-W641.

Malek, O., \& Knoop, V. (1998). Trans-splicing group II introns in plant mitochondria: The complete set of cis-arranged homologs in ferns, fern allies, and a hornwort. $R N A, 4(12)$, 1599-1609. doi: 10.1017/S1355838298981262

Mayne, B., Berry, O., Davies, C., Farley, J., \& Jarman, S. (2019). A genomic predictor of lifespan in vertebrates. Scientific Reports, 9(1), 17866. doi: 10.1038/s41598-019-54447-w

Mayne, B., Korbie, D., Kenchington, L., Ezzy, B., Berry, O., \& Jarman, S. (2020). A DNA methylation age predictor for zebrafish. Aging (Albany NY), 12(24), 24817-24835. doi: 10.18632/aging.202400

Medlyn, B., Barrett, D., Landsberg, J., Sands, P., \& Clement, R. (2003). Corrigendum to: Conversion of canopy intercepted radiation to photosynthate: a review of modelling approaches for regional scales. Functional Plant Biology, 30(7), 829-829. doi: 10.1071/fp02088_co

Meek, M. H., \& Larson, W. A. (2019). The future is now: Amplicon sequencing and sequence capture usher in the conservation genomics era. Molecular Ecology Resources, 19(4), 795-803. doi: 10.1111/1755-0998.12998

Meer, M. V., Podolskiy, D. I., Tyshkovskiy, A., \& Gladyshev, V. N. (2018). A whole lifespan mouse multi-tissue DNA methylation clock. Elife, 7, e40675.

Neale, D. B., Wegrzyn, J. L., Stevens, K. A., Zimin, A. V., Puiu, D., Crepeau, M. W., ... Langley, C. H. (2014). Decoding the massive genome of loblolly pine using haploid DNA and novel assembly strategies. Genome Biology, 15(3), R59. doi: 10.1186/gb-2014-15-3r59

Ng, H.-H., \& Adrian, B. (1999). DNA methylation and chromatin modification. Current Opinion in Genetics \& Development, 9(2), 158-163. doi: 10.1016/S0959-437X(99)80024-0

Ong-Abdullah, M., Ordway, J. M., Jiang, N., Ooi, S.-E., Kok, S.-Y., Sarpan, N., ... Martienssen, R. A. (2015). Loss of Karma transposon methylation underlies the mantled somaclonal variant of oil palm. Nature, 525(7570), 533-537. doi: 10.1038/nature15365

Parrott, B. B., \& Bertucci, E. M. (2019). Epigenetic aging clocks in ecology and evolution. Trends in Ecology \& Evolution, 34(9), 767-770. 
Partridge, L., \& Gems, D. (2002). Mechanisms of aging: Public or private? Nature Reviews Genetics, 3(3), 165-175.

Perls, T., Kunkel, L., \& Puca, A. (2002). The genetics of aging. Current Opinion in Genetics \& Development, 12(3), 362-369.

Perna, L., Zhang, Y., Mons, U., Holleczek, B., Saum, K.-U., \& Brenner, H. (2016). Epigenetic age acceleration predicts cancer, cardiovascular, and all-cause mortality in a German case cohort. Clinical Epigenetics, 8(1), 64. doi: 10.1186/s13148-016-0228-z

Probst, A. V., \& Mittelsten Scheid, O. (2015). Stress-induced structural changes in plant chromatin. Current Opinion in Plant Biology, 27, 8-16. doi: 10.1016/j.pbi.2015.05.011

Quinlan, A. R., \& Hall, I. M. (2010). BEDTools: A flexible suite of utilities for comparing genomic features. Bioinformatics, 26(6), 841-842. doi: 10.1093/bioinformatics/btq033

R Core Team (2021). R: A language and environment for statistical computing. R Foundation for Statistical Computing, Vienna, Austria. https://www.R-project.org/.

Raddatz, G., Arsenault, R. J., Aylward, B., Whelan, R., Böhl, F., \& Lyko, F. (2021). A chicken DNA methylation clock for the prediction of broiler health. Communications Biology, 4(1), 1-8. doi: 10.1038/s42003-020-01608-7

Revelle, W. (2019). psych: Procedures for psychological, psychometric, and personality research. Northwestern University, Evanston, Illinois. R package version 1.9. 12. URL

Http://CRAN. R-Project. Org/Package= Psych.

Richardson, B. (2003). Impact of aging on DNA methylation. Ageing Research Reviews, 2(3), 245-261. doi: 10.1016/S1568-1637(03)00010-2

Russell, J., \& Zomerdijk, J. C. B. M. (2005). RNA-polymerase-I-directed rDNA transcription, life and works. Trends in Biochemical Sciences, 30(2), 87-96. doi: 10.1016/j.tibs.2004.12.008

Ryan, C. P. (2021). "Epigenetic clocks": Theory and applications in human biology. American Journal of Human Biology, 33(3), e23488. doi: 10.1002/ajhb.23488

Ryan, C. P., Hayes, M. G., Lee, N. R., McDade, T. W., Jones, M. J., Kobor, M. S., ... Eisenberg, D. T. A. (2018). Reproduction predicts shorter telomeres and epigenetic age acceleration among young adult women. Scientific Reports, 8(1), 11100. doi: 10.1038/s41598-01829486-4

Samuelson, L., Stokes, T., Cooksey, T., \& McLemore III, P. (2001). Production efficiency of loblolly pine and sweetgum in response to four years of intensive management. Tree Physiology, 21(6), 369-376.

Schulze, M. D. (2003). Ecology and behavior of nine timber tree species in Pará, Brazil: Links between species life history and forest management and conservation. The Pennsylvania State University.

Shahryary, Y., Symeonidi, A., Hazarika, R. R., Denkena, J., Mubeen, T., Hofmeister, B., ... Johannes, F. (2020). AlphaBeta: Computational inference of epimutation rates and spectra from high-throughput DNA methylation data in plants. Genome Biology, 21(1), 260. doi: 10.1186/s13059-020-02161-6

Sharma, R., \& Patnaik, S. K. (1982). Differential Regulation of Malate Dehydrogenase Isoenzymes by Hydrocortisone in the Liver and Brain of Aging Rats. Development, Growth \& Differentiation, 24(5), 501-505. doi: 10.1111/j.1440-169X.1982.00501.x 
Simpkin, A. J., Suderman, M., Gaunt, T. R., Lyttleton, O., McArdle, W. L., Ring, S. M., ... Relton, C. L. (2015). Longitudinal analysis of DNA methylation associated with birth weight and gestational age. Human Molecular Genetics, 24(13), 3752-3763. doi: $10.1093 / \mathrm{hmg} / \mathrm{ddv} 119$

Slotkin, R. K., \& Martienssen, R. (2007). Transposable elements and the epigenetic regulation of the genome. Nature Reviews Genetics, 8(4), 272-285.

Stiff, C. T., \& Stansfield, W. F. (2003). Thinning guidelines for loblolly pine plantations in eastern Texas based on alternative management criteria. 12th Biennial Southern Silvicultural Research Conference, 323.

Stubbs, T. M., Bonder, M. J., Stark, A.-K., Krueger, F., Bolland, D., Butcher, G., ... BI Ageing Clock Team. (2017). Multi-tissue DNA methylation age predictor in mouse. Genome Biology, 18(1), 68. doi: 10.1186/s13059-017-1203-5

Suzuki, M. M., \& Bird, A. (2008). DNA methylation landscapes: Provocative insights from epigenomics. Nature Reviews Genetics, 9(6), 465-476. doi: 10.1038/nrg2341

Sweetman, C., Waterman, C. D., Rainbird, B. M., Smith, P. M. C., Jenkins, C. D., Day, D. A., \& Soole, K. L. (2019). AtNDB2 Is the Main External NADH Dehydrogenase in Mitochondria and Is Important for Tolerance to Environmental Stress1 [OPEN]. Plant Physiology, 181(2), 774-788. doi: 10.1104/pp.19.00877

Takuno, S., Ran, J.-H., \& Gaut, B. S. (2016). Evolutionary patterns of genic DNA methylation vary across land plants. Nature Plants, 2(2), 1-7. doi: 10.1038/nplants.2015.222

Tomaz, T., Bagard, M., Pracharoenwattana, I., Lindén, P., Lee, C. P., Carroll, A. J., ... Millar, A. H. (2010). Mitochondrial Malate Dehydrogenase Lowers Leaf Respiration and Alters Photorespiration and Plant Growth in Arabidopsis[W][OA]. Plant Physiology, 154(3), 1143-1157. doi: 10.1104/pp.110.161612

van der Graaf, A., Wardenaar, R., Neumann, D. A., Taudt, A., Shaw, R. G., Jansen, R. C., ... Johannes, F. (2015). Rate, spectrum, and evolutionary dynamics of spontaneous epimutations. Proceedings of the National Academy of Sciences, 112(21), 6676-6681. doi: 10.1073/pnas.1424254112

Weidner, C. I., Lin, Q., Koch, C. M., Eisele, L., Beier, F., Ziegler, P., ... Wagner, W. (2014). Aging of blood can be tracked by DNA methylation changes at just three $\mathrm{CpG}$ sites. Genome Biology, 15(2), R24. doi: 10.1186/gb-2014-15-2-r24

Weiss, H., Friedrich, T., Hofhaus, G., \& Preis, D. (1992). The respiratory-chain NADH dehydrogenase (complex I) of mitochondria. In P. Christen \& E. Hofmann (Eds.), EJB Reviews 1991 (pp. 55-68). Berlin, Heidelberg: Springer. doi: 10.1007/978-3-642-77200$9+5$

Xiao, F.-H., Wang, H.-T., \& Kong, Q.-P. (2019). Dynamic DNA Methylation During Aging: A "Prophet" of Age-Related Outcomes. Frontiers in Genetics, 0. doi: 10.3389/fgene.2019.00107

Yao, N., Schmitz, R. J., \& Johannes, F. (2021). Epimutations define a fast-ticking molecular clock in plants. Trends in Genetics.

Yudina, R. S. (2012). Malate dehydrogenase in plants: Its genetics, structure, localization and use as a marker. 2012. doi: 10.4236/abb.2012.34053

Zatsepina, O. V., Voit, R., Grummt, I., Spring, H., Semenov, M. V., \& Trendelenburg, M. F. (1993). The RNA polymerase I-specific transcription initiation factor UBF is associated 
with transcriptionally active and inactive ribosomal genes. Chromosoma, 102(9), 599_ 611. doi: 10.1007/BF00352307

Zhang, H., Lang, Z., \& Zhu, J.-K. (2018). Dynamics and function of DNA methylation in plants. Nature Reviews Molecular Cell Biology, 19(8), 489-506. doi: 10.1038/s41580-018-0016$\mathrm{Z}$

Zheng, Y., Joyce, B. T., Colicino, E., Liu, L., Zhang, W., Dai, Q., ... Hou, L. (2016). Blood Epigenetic Age may Predict Cancer Incidence and Mortality. EBioMedicine, 5, 68-73. doi: 10.1016/j.ebiom.2016.02.008

Zilberman, D. (2008). The evolving functions of DNA methylation. Current Opinion in Plant Biology, 11(5), 554-559. doi: 10.1016/j.pbi.2008.07.004

\section{Disclaimer}

This report was prepared as an account of work sponsored by an agency of the United States Government. Neither the United States Government nor any agency thereof, nor any of their employees, makes any warranty, express or implied, or assumes any legal liability or responsibility for the accuracy, completeness, or usefulness of any information, apparatus, product, or process disclosed, or represents that its use would not infringe privately owned rights. Reference herein to any specific commercial product, process, or service by tradename, trademark, manufacturer, or otherwise does not necessarily constitute or imply its endorsement, recommendation, or favoring by the United States Government or any agency thereof. The views and opinions of authors expressed herein do not necessarily state or reflect those of the United States Government or any agency thereof.

Data accessibility: Data used to support the claims in this manuscript will be made publicly available in the NCBI Sequence Read Archive (SRA) upon acceptance for publication. Scripts used to analyze data will be publicly available at https://github.com/stg0015/Loblolly-scripts. 


\section{Author contributions:}

698 E.M.B., B.B.P, D.P.A., and A.H. developed the concept for the paper. E.M.B. and R.S. collected

699 the samples. E.M.B. prepared the libraries and assisted S.G. with data analysis. S.G. analyzed the

700 data and wrote the paper while being assisted by E.M.B. and B.B.P. 
(A) CpG

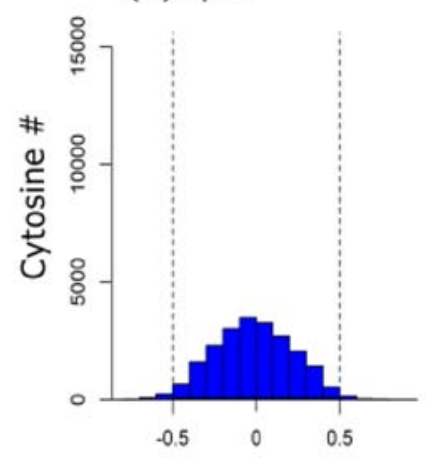

(B) $\mathrm{CHG}$

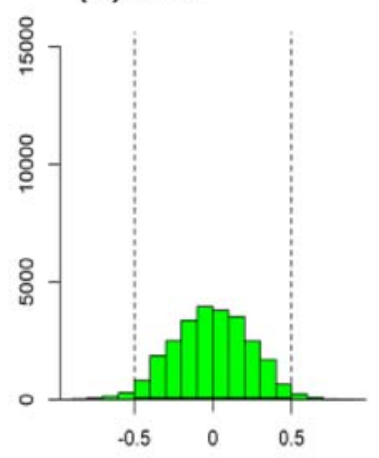

(C) $\mathrm{CHH}$

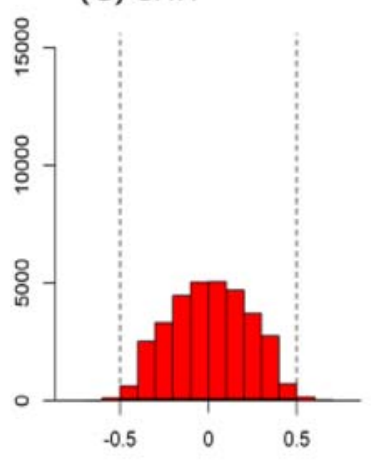

Correlation of methylation status with age

Figure 1. Distributions of Spearman correlation coefficients of cytosine methylation status with age following filtering of invariant sites across $\mathrm{CpG}, \mathrm{CHG}$, and $\mathrm{CHH}$ methylation contexts from 24 Loblolly pine trees of differing ages. (A) Of 21,567 CpGs analyzed, 533 (2.5\%) showed correlations between methylation status and age of $\mathrm{R}>|0.5|$. (B) Of 25,501 CHGs analyzed, 869 (3.4\%) displayed correlations between methylation status and age of $\mathrm{R}>|0.5|$. (C) Of 33,151 CHHs analyzed, $308(0.93 \%)$ showed correlations between age and methylation status of R > |0.5|. 
Figure 2. Enrichment and depletion of age-related DNA methylation within genomic regions with varying $\mathrm{CpG}$ densities. Cytosines for which methylation status was associated with age $(\mid \mathrm{R}>$ 0.5|) were compared against all RBSS-captured cytosines (background). (A) Age-associated CpG methylation was enriched in $\mathrm{CpG}$ island and shore regions and were depleted in $\mathrm{CpG}$ shelf and open-sea regions. (B) Age-associated CHG methylation was enriched in $\mathrm{CpG}$ islands and depleted in shore regions. (C) There were no differences in the distributions of age-associated $\mathrm{CHH}$-methylated cytosines compared to background $\mathrm{CHH}$ methylated cytosine levels (Asterisks indicate $P<0.05$ ). 
Figure 3. Elastic net models used to predict chronological age in P. taeda for both training and
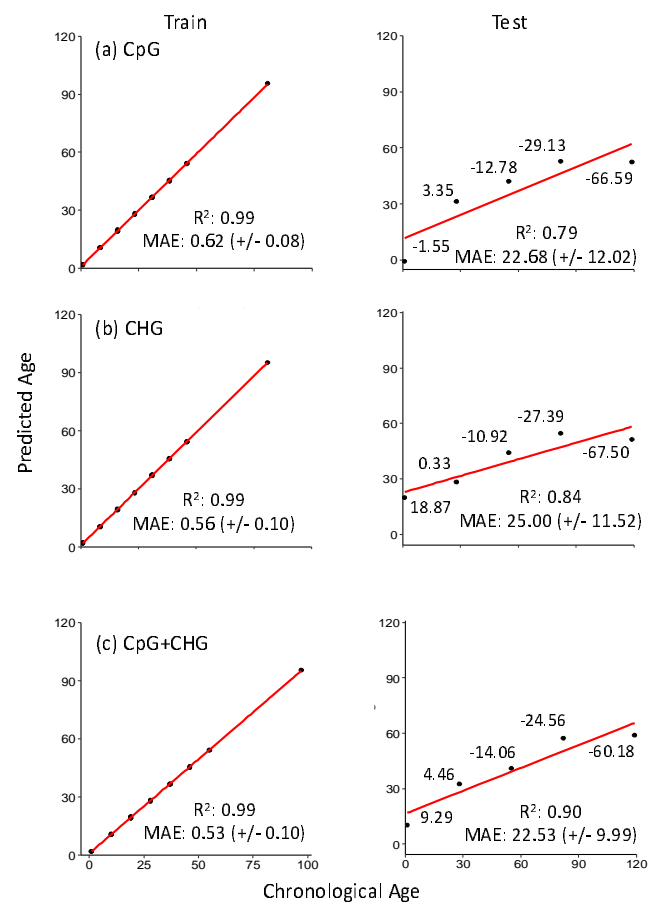
test subsets. Clock accuracy is measured by the Pearson's correlation coefficient and precision by the mean absolute error (MAE) (+/- standard error). (A) $35 \mathrm{CpGs}$ out of 18,844 CpGs following invariant filtering were selected in our elastic net model. (B) $50 \mathrm{CHGs}$ out of 22,263 CHGs were 

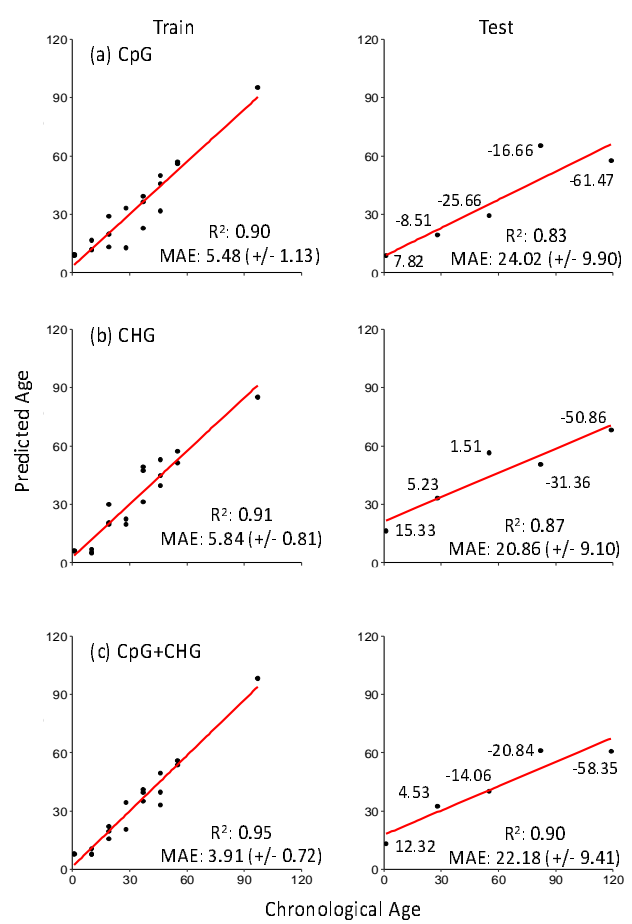

Figure 4. Pearson models incorporating the five cytosines with the strongest age-associated methylation patterns predict chronological ages in $P$. taeda for both training and test subsets for $\mathrm{CpG}, \mathrm{CHG}$, and combined ( $\mathrm{CpG}+\mathrm{CHG})$ models. Clock accuracy is measured by the Pearson's correlation coefficient and precision by the mean absolute error (MAE) (+/- standard error). Values of individual datapoints represent the error between predicted ages from our models compared to chronological ages among our test individuals, with positive values indicating overestimation and negative values indicating underestimation of chronological age. 
bioRxiv preprint doi: https://doi. org/10.1101/2022 0127.477887; this version posted January 28, 2022. The copyright holder for this preprint (which was not certified by peer review) is the author/funder, who has granted bioRxiv a license to display the preprint in perpetuity. It is made available under aCC-BY-NC-ND 4.0 International license.

750 Table 1. Distributions of hypo- (-) and hypermethylated (+) cytosines with age among genomic 751 regions

\begin{tabular}{|c|c|c|c|c|c|c|c|c|c|}
\hline \multirow[t]{2}{*}{ Context } & \multirow[t]{2}{*}{ Cytosine subset } & \multicolumn{2}{|c|}{ Island Cytosines } & \multicolumn{2}{|c|}{ Shore Cytosines } & \multicolumn{2}{|c|}{ Shelf Cytosines } & \multicolumn{2}{|c|}{ Open sea cytosines } \\
\hline & & - & + & - & + & - & + & - & + \\
\hline \multirow[t]{2}{*}{$\mathrm{CpG}$} & Age-associated & 111 & 14 & 56 & 35 & 7 & 9 & 152 & 149 \\
\hline & Significantly correlated & 2 & 0 & 2 & 1 & 0 & 0 & 4 & 1 \\
\hline \multirow[t]{2}{*}{$\mathrm{CHG}$} & Age-associated & 105 & 24 & 57 & 30 & 33 & 27 & 325 & 269 \\
\hline & Significantly correlated & 21 & 0 & 5 & 1 & 1 & 0 & 33 & 9 \\
\hline $\mathrm{CHH}$ & Age-associated & 7 & 14 & 20 & 14 & 11 & 12 & 84 & 147 \\
\hline
\end{tabular}

752

753

754

755

756 
bioRxiv preprint doi: https://doi.org/10.1101/2022 0127.477887; this version posted January 28, 2022. The copyright holder for this preprint (which was not certified by peer review) is the author/funder, who has granted bioRxiv a license to display the preprint in perpetuity. It is made available under aCC-BY-NC-ND 4.0 International license.

757 Table 2. Performance of elastic net models when predicting ages of trees from training and test

\begin{tabular}{|c|c|c|c|c|c|c|c|c}
\hline \multicolumn{10}{|c|}{ Elastic Net } \\
\hline Context & $\begin{array}{c}\text { \# Initial } \\
\text { sites }\end{array}$ & $\begin{array}{c}\text { \# Filtered } \\
\text { sites }\end{array}$ & $\begin{array}{c}\text { \# Clock } \\
\text { sites }\end{array}$ & $\begin{array}{c}\text { Train } \\
\text { R2 }\end{array}$ & $\begin{array}{c}\text { Train MAE } \\
\text { (years) }\end{array}$ & $\begin{array}{c}\text { Test } \\
\text { R2 }\end{array}$ & $\begin{array}{c}\text { Test MAE } \\
\text { (years) }\end{array}$ & Overfit? (t-test p-value) \\
\hline CpG & 26520 & 18844 & 35 & 0.9998 & $0.62(+/-0.08)$ & 0.79 & $\begin{array}{c}22.68(+/- \\
12.02)\end{array}$ & No $(0.14)$ \\
\hline CHG & 30728 & 22263 & 50 & 0.9999 & $0.56(+/-0.10)$ & 0.843 & $\begin{array}{c}25.00(+/- \\
11.52)\end{array}$ & No $(0.10)$ \\
\hline CpG+CHG & 57248 & 41107 & 47 & 0.9999 & $0.53(+/-0.10)$ & 0.899 & $\begin{array}{c}22.53(+/- \\
9.99)\end{array}$ & No $(0.09)$ \\
\hline
\end{tabular}

758 sets

759

760

761

762

763

764

765 
Table 3. Combined $\mathrm{CpG}$ and $\mathrm{CHG}$ elastic net model

\begin{tabular}{|c|c|c|c|c|c|c|c|c|c|c|}
\hline te & Context & Scaffold & Position & Pearson Correlation & $P$ value & Cytosine region & Blast (400 bp window) & Score & E value & Model Coefficient \\
\hline 33 & CPG & APFE030056171.1 & 85519 & 0.654965751 & 0.1790736 & Shore & gb|AC241314.1| Pinus taeda clone PT_7Ba3152O20, complete sequence & 420 & 0 & $1.92 \mathrm{E}-02 \zeta$ \\
\hline 70 & CpG & APFE030124122.1 & 12062 & 0.766388533 & 0.03356732 & Open Sea & gb| BT124256.1| Picea sitchensis clone WS0472_E12 unknown mRNA & 70 & $7.00 \mathrm{E}-08$ & $6.13 \mathrm{E}-02 \stackrel{?}{\mathrm{~S}}$ \\
\hline 95 & $\mathrm{CPG}$ & APFE030296703.1 & 22823 & 0.635707517 & 0.2388488 & Shore & gb|CP023113.2| Lupinus angustifolius cultivar Tanjil chromosome ... & 46 & $1.00 \mathrm{E}+00$ & $4.04 \mathrm{E}-02=\frac{\bar{\nabla}}{8}$ \\
\hline 92 & $\mathrm{CpG}$ & APFE030429279.1 & 23186 & 0.426113678 & 0.7692602 & Open Sea & ref|XM_002178996.1| Phaeodactylum tricornutum CCAP 1055/1 predic.. & 50 & $4.80 \mathrm{E}-02$ & $2.15 \mathrm{E}-02 \stackrel{\overbrace{}}{\beth}$ \\
\hline 87 & $\mathrm{CpG}$ & APFE030610080.1 & 1827 & -0.618603432 & 0.2685608 & Island & $\mathrm{gb}|\mathrm{KY} 860920.1|$ Pinus resinosa 26S ribosomal RNA gene, partial se... & 559 & $0.00 \mathrm{E}+00$ & $-1.43 \mathrm{E}-02 \mathrm{O}$ \\
\hline$\underline{L 5}$ & $\mathrm{CPG}$ & APFE030649645.1 & 41591 & -0.595468448 & 0.2685608 & Open Sea & gb|DQ987890.1| Picea smithiana 18S ribosomal RNA gene, partial s... & 236 & $5.00 \mathrm{E}-58$ & $-1.19 \mathrm{E}-02 \stackrel{8}{\mathbb{D}}$ \\
\hline 374 & CpG & APFE030665456.1 & 32141 & -0.454116977 & 0.676632 & Island & gb|AC241277.1| Pinus taeda clone PT_7Ba0032C08, complete sequence & 72 & $2.00 \mathrm{E}-08$ & $-2.48 \mathrm{E}-02 \stackrel{\mathrm{D}}{\leq}$ \\
\hline 146 & $\mathrm{CpG}$ & APFE030813233.1 & 186110 & 0.628514942 & 0.24590978 & Shore & gb|HM853297.1| Pinus pinaster malate dehydrogenase (mdhB) gene, ... & 244 & $2.00 \mathrm{E}-60$ & $1.62 \mathrm{E}-02 \mathrm{~s}$ \\
\hline 147 & $\mathrm{CpG}$ & APFE030813233.1 & 186111 & 0.810819503 & 0.01143114 & Shore & gb|HM853297.1| Pinus pinaster malate dehydrogenase (mdhB) gene, ... & 244 & $2.00 \mathrm{E}-60$ & 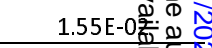 \\
\hline 365 & $\mathrm{CPG}$ & APFE030896286.1 & 7992 & 0.520639615 & 0.4273731 & Open Sea & $\mathrm{gb}$ | KM244285.1| Pinus ayacahuite isolate E4095 NADH dehydrogenase... & 72 & $2.00 \mathrm{E}-08$ & 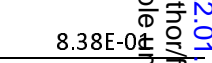 \\
\hline 43 & $\mathrm{CpG}$ & APFE030921614.1 & 53436 & 0.638958619 & 0.2314296 & Open Sea & gb|AC241337.1| Pinus taeda clone PT_7Ba3875B09, complete sequence & 82 & $2.00 \mathrm{E}-11$ & 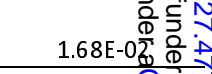 \\
\hline 746 & CpG & APFE031018063.1 & 67260 & 0.809419608 & 0.01143114 & Open Sea & gb| BT124256.1| Picea sitchensis clone WS0472_E12 unknown mRNA & 62 & $2.00 \mathrm{E}-05$ & $5.21 \mathrm{E}-0 \mathrm{z}$ \\
\hline 60 & $\mathrm{CpG}$ & APFE031293786.1 & 340 & -0.657638981 & 0.175754 & Open Sea & gb| KY860920.1| Pinus resinosa 26S ribosomal RNA gene, partial se... & 591 & $0.00 \mathrm{E}+00$ & $-1.70 \mathrm{E}-\mathrm{C}_{2}$ \\
\hline$; 99$ & CpG & APFE031355998.1 & 7890 & -0.656292592 & 0.1774374 & Shore & gb|KY860920.1| Pinus resinosa 26S ribosomal RNA gene, partial se.. & 747 & $0.00 \mathrm{E}+00$ & $-2.91 \mathrm{E}-0.02 \frac{0}{2}$ \\
\hline 133 & CpG & APFE031387609.1 & 58957 & 0.697040128 & 0.1108949 & Open Sea & emb|AM460409.1| Vitis vinifera, whole genome shotgun sequence, $\mathrm{c} . .$. & 50 & $6.40 \mathrm{E}-02$ & $1.28 \mathrm{E}-0 \overline{\frac{9}{6}}$ 음 \\
\hline 187 & $\mathrm{CpG}$ & APFE031573243.1 & 563 & -0.39575534 & 0.873483 & Open Sea & gb|AC241294.1| Pinus taeda clone PT_7Ba2900I02, complete sequence & 456 & $0.00 E+00$ & 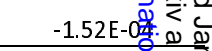 \\
\hline 33 & CHG & APFE030022174.1 & 103673 & -0.631271133 & 0.24523123 & Shelf & emb|CR378014.1| Pinus pinaster SSR, clone PPB1C11 & 168 & $1.00 E-37$ & -4.70E-03. \\
\hline 55 & CHG & APFE030116531.1 & 169841 & 0.437955931 & 0.736395 & Open Sea & ref|NC_039746.1| Pinus Taeda mitochondrion, complete genome & 696 & 0 & 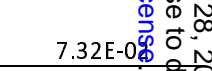 \\
\hline 95 & CHG & APFE030198195.1 & 116 & 0.456408321 & 0.6683698 & Open Sea & ref|NG_052992.1| Homo sapiens zinc finger and BTB domain contain... & 52 & 0.016 & $2.93 E+00 \frac{\overline{0}}{N}$ \\
\hline 02 & CHG & APFE030266102.1 & 32477 & 0.764090945 & 0.03356732 & Open Sea & $\mathrm{gb}|J 0519677.1|$ Rhopalosoma sp. SK-2012 voucher DM400 elongation ... & 56 & $1.00 \mathrm{E}-03$ & $1.60 \mathrm{E}-02$ 宫 \\
\hline 03 & CHG & APFE030266102.1 & 32482 & 0.746860297 & 0.04826154 & Open Sea & $\mathrm{gb}|J 0519677.1|$ Rhopalosoma sp. SK-2012 voucher DM400 elongation ... & 56 & $1.00 \mathrm{E}-03$ & $1.94 \mathrm{E}-02 \stackrel{\mathrm{t}}{\equiv}$ \\
\hline 93 & CHG & APFE030339785.1 & 101999 & 0.707142325 & 0.09913354 & Open Sea & gb|AC241312.1| Pinus taeda clone PT_7Ba3106J15, complete sequence & 64 & 4.00E-06 & $6.97 \mathrm{E}-02$ 궁 \\
\hline 32 & CHG & APFE030384252.1 & 33429 & 0.475514945 & 0.5982055 & Open Sea & $\mathrm{gb}|\mathrm{CP} 020630.1|$ Oryzias latipes strain HSOK chromosome 10 & 44 & $3.90 \mathrm{E}+00$ & $4.92 \mathrm{E}-02 \stackrel{\mathbb{\Phi}}{\rightleftarrows}$ \\
\hline 59 & CHG & APFE030474771.1 & 62256 & -0.663102568 & 0.1617216 & Open Sea & gb|AC241319.2| Pinus taeda clone PT_7Ba3200G14, complete sequence & 129 & $9.00 \mathrm{E}-26$ & $3.93 \mathrm{E}-02 \stackrel{-}{=}$ \\
\hline
\end{tabular}




\begin{tabular}{|c|c|c|c|c|c|c|c|c|c|c|}
\hline 91 & CHG & APFE030543629.1 & 29207 & 0.671762877 & 0.1433964 & Open Sea & $\mathrm{gb}|\mathrm{KM} 244267.1|$ Pinus merkusii isolate 919/1 NADH dehydrogenase s... & 248 & $1.00 \mathrm{E}-61$ & $6.18 \mathrm{E}-02$ \\
\hline $\mathbf{i 4 1}$ & $\mathrm{CHG}$ & APFE030641925.1 & 181993 & 0.731095016 & 0.06161909 & Shore & $\mathrm{gb}$ |HM853297.1| Pinus pinaster malate dehydrogenase (mdhB) gene, ... & 194 & $2.00 \mathrm{E}-45$ & $8.83 \mathrm{E}-$ \\
\hline 196 & CHG & APFE030845544.1 & 125944 & -0.605217158 & 0.2685608 & Open Sea & $\mathrm{gb} \mid \mathrm{AC241347.1|}$ Pinus taeda clone PT_7Ba4144L02, complete sequence & 111 & $2.00 \mathrm{E}-20$ & $-8.22 \mathrm{E}$ \\
\hline$: 61$ & CHG & APFE030912860.1 & 23919 & -0.786726873 & 0.01950128 & Open Sea & $\mathrm{gb}|\mathrm{AC} 241341.1|$ Pinus taeda clone PT_7Ba4050C22, complete sequence & 101 & $2.00 \mathrm{E}-17$ & $-2.30 \mathrm{E}-$ \\
\hline$! 65$ & CHG & APFE030912860.1 & 23958 & -0.768712593 & 0.03356732 & Open Sea & 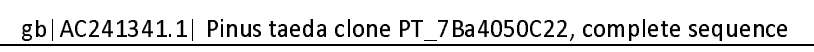 & 101 & $2.00 \mathrm{E}-17$ & -1.9 \\
\hline 997 & CHG & APFE030944291.1 & 28610 & -0.474078374 & 0.60426607 & Open Sea & $\mathrm{gb}|J \mathrm{Q} 262265.1|$ Pinus radiata isolate 5586 anonymous locus $0 \_1789$. & 117 & $3.00 \mathrm{E}-22$ & $-7.98 \mathrm{E}$ \\
\hline 18 & CHG & APFE030960074.1 & 37277 & -0.584417322 & 0.2685608 & Shore & gb|AC241357.1| Pinus taeda clone PT_7Ba4350E08, complete sequence & 466 & $0.00 E+00$ & -1 . \\
\hline$\lcm{19}$ & CHG & APFE030960074.1 & 37304 & -0.520006454 & 0.4296008 & Shore & gb|AC241357.1| Pinus taeda clone PT_7Ba4350E08, complete sequence & 466 & $0.00 E+00$ & -2.13 \\
\hline 222 & CHG & APFE030995986.1 & 235721 & -0.66335366 & 0.16172156 & Island & $\mathrm{gb}|\mathrm{AC} 241265.2|$ Pinus taeda clone PT_7Ba0002H13, complete sequence & 74 & $4.00 \mathrm{E}-09$ & $-3.77 \mathrm{E}-0 \frac{3}{2}$ \\
\hline 223 & CHG & APFE030995986.1 & 235730 & -0.84349085 & 0.00465065 & Island & $\mathrm{gb}|\mathrm{AC} 241265.2|$ Pinus taeda clone PT_7Ba0002H13, complete sequence & 74 & $4.00 \mathrm{E}-09$ & $-5.42 \mathrm{E}-0 \mathrm{C}=\mathrm{E}$ \\
\hline 2 & CHG & APFE030995986.1 & 235737 & -0.7415851 & 0.05307257 & Island & $\mathrm{gb}|\mathrm{AC} 241265.2|$ Pinus taeda clone PT_7Ba0002H13, complete sequence & 74 & $4.00 \mathrm{E}-09$ & \\
\hline 194 & CHG & APFE031021371.1 & 131664 & 0.634258251 & 0.2395202 & Open Sea & $\mathrm{gb}|\mathrm{AC} 241265.2|$ Pinus taeda clone PT_7Ba0002H13, complete sequence & 272 & $9.00 \mathrm{E}-69$ & 4.7 \\
\hline 179 & CHG & APFE031170467.1 & 52691 & -0.80960342 & 0.01143114 & Island & gb|AC241357.1| Pinus taeda clone PT_7Ba4350E08, complete sequence & 196 & $4.00 E-46$ & $-2.09 \mathrm{E}-\mathrm{Cg}$ \\
\hline 61 & CHG & APFE031246774.1 & 57161 & 0.16958204 & 0.9928919 & Island & gb|AC241265.2| Pinus taeda clone PT_7Ba0002H13, complete sequence & 90 & $7.00 \mathrm{E}-14$ & 4.27E-0.998 \\
\hline$\underline{57}$ & CHG & APFE031412923.1 & 164330 & 0.570400422 & 0.2794292 & Open Sea & $\mathrm{gb}|\mathrm{HM} 853297.1|$ Pinus pinaster malate dehydrogenase (mdhB) gene, Ö & 170 & $3.00 E-38$ & $2.86 \mathrm{E}-03$ \\
\hline 168 & $\mathrm{CHG}$ & APFE031420108.1 & 79663 & -0.482785312 & 0.5711723 & Open Sea & emb|LR131964.1| Parambassis ranga genome assembly, chromosome: 14 & 44 & $3.90 \mathrm{E}+00$ & $-2.87 \mathrm{E}-02$ \\
\hline 343 & CHG & APFE031468650.1 & 339818 & -0.638966355 & 0.2314296 & Shore & $\mathrm{gb} \mid \mathrm{AC241351.1|}$ Pinus taeda clone PT_7Ba4290D18, complete sequence & 444 & $0.00 E+00$ & $-4.08 \mathrm{E}-03$ \\
\hline 171 & CHG & APFE031470839.1 & 87114 & 0.560775989 & 0.30052775 & Open Sea & $\mathrm{gb} \mid \mathrm{AC241310.1|}$ Pinus taeda clone PT_7Ba3100G06, complete sequence & 68 & $3.00 \mathrm{E}-07$ & $3.71 \mathrm{E}-02$ \\
\hline 04 & CHG & APFE031487846.1 & 62255 & -0.670249113 & 0.1433964 & Island & gb|CP009524.1| Methanosarcina sp. Kolksee, complete genome & 62 & $2.00 E-05$ & $-2.09 \mathrm{E}-02$ \\
\hline 362 & CHG & APFE031619745.1 & 77285 & -0.634856423 & 0.2395202 & Shore & 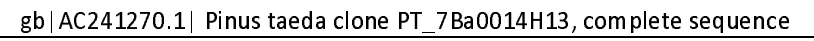 & 240 & $3.00 E-59$ & $-3.40 \mathrm{E}-03$ \\
\hline \multirow[t]{2}{*}{168} & CHG & APFE031626435.1 & 55430 & -0.749901258 & 0.04805051 & Open Sea & $\mathrm{gb}|J \mathrm{Q} 262265.1|$ Pinus radiata isolate 5586 anonymous locus $0 \_1789 .$. & 101 & $2.00 \mathrm{E}-17$ & $-3.29 \mathrm{E}-02$ \\
\hline & & & & & & & & & Intercept & 38.04695 \\
\hline
\end{tabular}


Table 4. Performance of Pearson models when predicting ages of trees from training and test sets

\begin{tabular}{|c|c|c|c|c|c|c|c|}
\hline \multicolumn{8}{|c|}{ Pearson Model (5 cytosines) } \\
\hline Context & $\begin{array}{c}\text { \# Initial } \\
\text { sites }\end{array}$ & $\begin{array}{c}\text { \# Filtered } \\
\text { sites }\end{array}$ & $\begin{array}{c}\text { Train } \\
\text { R2 }\end{array}$ & $\begin{array}{c}\text { Train MAE } \\
\text { (years })\end{array}$ & $\begin{array}{c}\text { Test } \\
\text { R2 }\end{array}$ & $\begin{array}{c}\text { Test MAE } \\
\text { (years })\end{array}$ & $\begin{array}{c}\text { Overfit? (t-test p- } \\
\text { value) }\end{array}$ \\
\hline CpG & 26520 & 18844 & 0.898 & $5.48(+/-1.13)$ & 0.829 & $24.02(+/-9.9)$ & No $(0.13)$ \\
\hline CHG & 30728 & 22263 & 0.911 & $5.84(+/-0.81)$ & 0.873 & $20.86(+/-9.10)$ & No $(0.17)$ \\
\hline CpG+CHG & 57248 & 41107 & 0.952 & $3.91(+/-0.72)$ & 0.9 & $22.18(+/-9.41)$ & No $(0.12)$ \\
\hline \multicolumn{7}{|c|}{ Pearson Model $(10$ cytosines) } \\
\hline Context & $\begin{array}{c}\text { \# Initial } \\
\text { sites }\end{array}$ & $\begin{array}{c}\text { \# Filtered } \\
\text { sites }\end{array}$ & $\begin{array}{c}\text { Train } \\
\text { R2 }\end{array}$ & $\begin{array}{c}\text { Train MAE } \\
\text { (years })\end{array}$ & $\begin{array}{c}\text { Test } \\
\text { R2 }\end{array}$ & Test MAE \\
(years $)$ & \\
\hline CpG & 26520 & 18844 & 0.943 & $4.07(+/-0.84)$ & 0.03 & $38.14(+/-19.03)$ & No $(0.15)$ \\
\hline CHG & 30728 & 22263 & 0.972 & $3.28(+/-0.45)$ & 0.58 & $22.08(+/-13.41)$ & No $(0.23)$ \\
\hline CpG+CHG & 57248 & 41107 & 0.979 & $2.59(+/-0.5)$ & 0.87 & $21.12(+/-9.01)$ & No $(0.11)$ \\
\hline
\end{tabular}


Table 5. Combined $\mathrm{CpG}$ and Pearson models (5 and 10 cytosines)

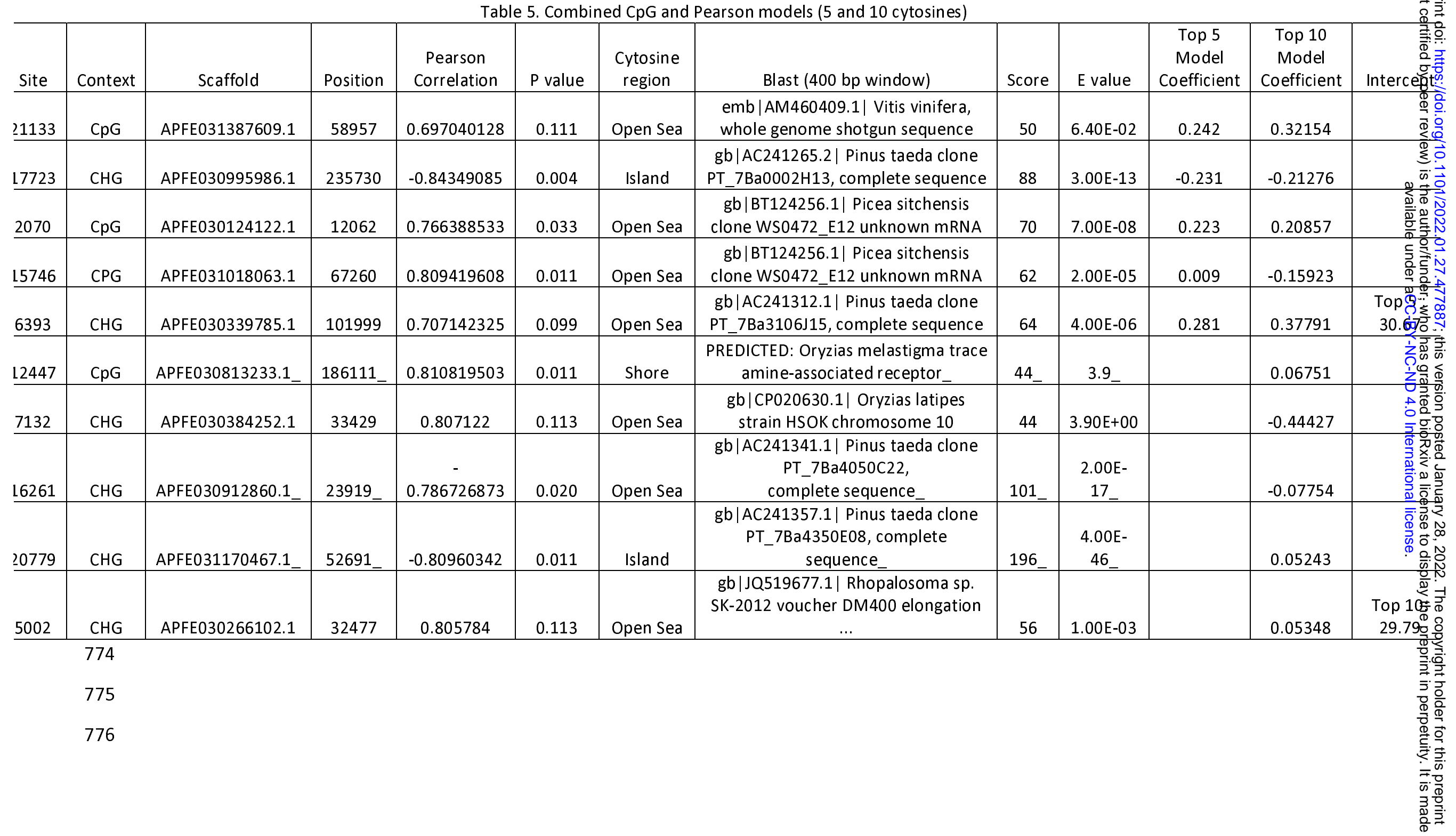

